\title{
Geleitwort zum BHM-Jubiläumsheft 175-Jahre Montanuniversität
}

\author{
Online publiziert am 29. Oktober 2015
}

Die Montanuniversität feiert heuer ihr 175-jähriges Bestehen. Ausgehend vom Berg- und Hüttenwesen wurden die Forschungs- und Lehrkompetenzen entlang derWertschöpfungskette, die von der Rohstoffgewinnung und -aufbereitung, über die Metallurgie, die Hochleistungswerkstoffe, das Prozess- und Produktengineering, die Umwelttechnik und Abfallwirtschaft reichen, konsequent weiter ausgebaut und durch die Energietechnik und das Recycling ergänzt, sodass wir heute richtiger von einem Wertschöpfungskreislauf als von einerWertschöpfungskette sprechen können. Damit erfüllt die Montanuniversität einen wichtigen Beitrag zur Bewältigung zukünftiger Herausforderungen unserer Gesellschaft.

Das Wirken der Montanuniversität war von Anfang an geprägt durch Forschung, Lehre und Zusammenarbeit mit der Wirtschaft. Der Bergbau und das Hüttenwesen schufen die Grundlage für die wirtschaftliche Entwicklung des Alpenraums. Ein wesentlicher Rohstofflieferant war der Erzberg, von dem sich sowohl nach Norden als auch nach Süden eisenverarbeitende Betriebe und Handelshäuser ansiedelten. Auf Anregung von Erzherzog Johann wurde durch die Kuratoren des im Jahre 1811 als technische hohe Schule gegründeten Joanneums in Graz der Antrag auf Errichtung einer Lehrkanzel für Eisenhüttenkunde gestellt. Diese Lehrkanzel wurde in Vordernberg, dem damals bedeutendsten Ort des alpenländischen Eisenwesens, eingerichtet. Am 4. November 1840 wurde die Lehranstalt offiziell eröffnet, dieses Datum ist damit das Gründungsdatum der Montanuniversität.

Studierten im Jahre 1900 etwa 300 Hörer an der Montanuniversität, so ist diese Zahl im Studienjahr 2014/2015 auf knapp 4000 Studierende angewachsen, wobei 2014/2015 die Zahl an Studienanfängern mit 737 einen neuen Höchststand erreichte. Der Anteil an ausländischen Studierenden beträgt $16 \%$, wobei die internationalen Studierenden aus rund 80 Nationen kommen. Die erste Frau inskribierte im Jahre 1916 an der Montanuniversität, heute beträgt der Frauenanteil unter den Studierenden $24 \%$.

Nicht unerheblich ist die hohe Zahl der Doktoratsstudierenden, die auch ein Ausdruck für die hohe Forschungsaktivität an der Montanuniversität ist: Im Studienjahr 2014/2015 waren 304 Doktoratsstudierende inskribiert.

Die Montanuniversität Leoben ist seit jeher eng mit Industrie und Wirtschaft verbunden, was sich unter anderem in einem hohen Maß an Drittmitteln ausdrückt. So machen im
Durchschnitt der Jahre 2012 bis 2014 die Einnahmen aus den Drittmittelprojekten etwa $35 \%$ des Gesamtbudgets aus. Zahlreiche Forschungsprojekte werden dadurch erst ermöglicht, was sich $u$. a. in den 557 durch Drittmittel finanzierten Personen ausdrückt, bei einem Personalstand von 1259 Mitarbeitern. Niederschlag findet die Zusammenarbeit mit der Industrie auch in den Comet-Zentren, an denen die Montanuniversität beteiligt ist, wie dem MCL, dem PCCL, dem K1Met oder dem EvoLET. Eingebettet in die Universität sind auch zahlreiche Christian Doppler Labors: Seit 1990 wurden 21 CD-Labors eingerichtet, die häufig die Initialzündung für neue Forschungsbereiche an der Montanuniversität bildeten.

Massiv erhöht werden konnten die internationalen Aktivitäten in den letzten Jahren: Insgesamt war die Montanuniversität Leoben seit 2004 an 76 EU-Projekten mit einem Gesamtvolumen von rund 17,5 Mio. Euro beteiligt. Davon sind 201514 Projekte mit einem Volumen in der Höhe von etwa sechs Millionen Euro im Laufen.

Die internationale Bedeutung wird auch durch ein im Jahre 2014 genehmigtes EU-Forschungszentrum, die Knowledge and Innovation Community (KIC) für Rohstoffe, unterstrichen, welches insgesamt 116 Forschungspartner in halb Europa zusammenbringt.

Unterstützung für Spin-offs gibt es im Zentrum für AngewandteTechnologie, dem ZAT, an dem die Montanuniversität neben der Stadt Leoben beteiligt ist. Hier werden Firmengründer von ihrer ersten Phase weg bis zur Etablierung am Markt begleitet. Seit der Eröffnung im Jahre 1999 wurden hier rund 50 Gründer unterstützt.

Alles in allem, eine sehr erfolgreiche Entwicklung unserer Universität in den vergangenen 175 Jahren!

\section{Glück auf!}

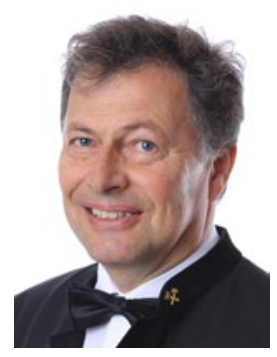

Wilfried Eichlseder Leoben, Österreich wilfried.eichlseder@unileoben.ac.at 